\title{
VARIABILIDADE ESPACIAL DA RESISTÊNCIA MECÂNICA À PENETRAÇÃO EM VERTISSOLO CULTIVADO COM MANGA NO PERÍMETRO IRRIGADO DE MANDACARU, JUAZEIRO, BAHIA, BRASIL $^{(1)}$
}

\author{
Daniela Siqueira Coelho( ${ }^{(2)}$, Jorge Wilson Cortez ${ }^{(3)} \&$ Nelci Olszevski(3)
}

\begin{abstract}
RESUMO
A resistência do solo à penetração é um parâmetro frequentemente utilizado como indicador da compactação do solo em sistemas de manejo, podendo relacioná-lo diretamente com o crescimento e a produtividade das culturas em geral. Para isso, é importante a utilização de métodos geoestatísticos em sua avaliação, por considerar a heterogeneidade dos dados ao longo da área. $O$ objetivo deste trabalho foi avaliar a variabilidade espacial da resistência mecânica do solo à penetração (RP) em um Vertissolo cultivado com manga. A coleta de dados foi realizada em área do Projeto Mandacaru I, em Juazeiro-BA, utilizando um penetrômetro eletrônico para determinação da RP nas camadas de $0,00-0,10,0,10-0,20,0,20-0,30$ e $0,30-0,40 \mathrm{~m}$ e um GPS de navegação para determinação da posição geográfica dos pontos. Também foram feitas coletas de amostras de solo, para determinação da umidade e da textura. Na análise dos resultados foram utilizadas a estatística descritiva e a aplicação da geoestatística. A partir dos resultados, pôde-se constatar aumento da RP ao longo das camadas mais profundas, podendo atingir níveis acima de $3,000 \mathrm{kPa}$ em zonas específicas da área. Por meio desses resultados, é possível monitorar a compactação, que se mostrou crítica em determinados pontos, e realizar o manejo do solo em pontos localizados, dependendo do nível de compactação.
\end{abstract}

Termos de indexação: compactação, profundidade, geoestatística.

\footnotetext{
(1) Parte do Trabalho de Conclusão de Curso do primeiro autor em Engenharia Agrícola e Ambiental. Universidade Federal do Vale do São Francisco. Recebido para publicação em 2 de dezembro de 2011 e aprovado em 30 de março de 2012.

(2) Mestranda em Engenharia Agrícola e Ambiental, Universidade Federal do Vale do São Francisco. Av. Avenida Antonio Carlos Magalhães 510, Santo Antônio CEP 48902-300 Juazeiro (BA). Bolsista CAPES. E-mail: daniela.coelho@hotmail.com.br

(3) Professor Adjunto, Universidade Federal do Vale do São Francisco - UNIVASF. Av. José de Sá Maniçoba s/n, Centro, CEP 56304917 Petrolina (PE). E-mails: jorge.cortez@univasf.edu.br; nelci.olszevski@univasf.edu.br
} 


\title{
SUMMARY: SPATIAL VARIABILITY OF SOIL PENETRATION RESISTANCE OF A VERTISOL UNDER MANGO IN PERIMETER OF IRRIGATED MANDACARU IN JUAZEIRO, BAHIA, BRAZIL
}

\begin{abstract}
Soil resistance to penetration is frequently used as an indicator of soil compaction in management systems and can be directly related to crop growth and yields in general. It is important to use geostatistical methods in the assessment of soil resistance to penetration by considering the data heterogeneity of the area. The purpose of this study was to evaluate the spatial variability of soil penetration resistance $(P R)$ in a Vertisol with mango trees. Data collection was performed in the Project area Mandacaru I in Juazeiro, Bahia, Brazil, by using an electronic penetrometer for determination of $P R$ in the layers 0.00-0.10, 0.10-0.20, $0.20-0.30$, and $0.30-0.40 \mathrm{~m}$ and a GPS navigation system to determine the geographic position. Soil samples were also collected to determine soil moisture and texture. For data analysis, descriptive statistics and geostatistics were used. Results showed an increase in $P R$ in the deeper layers, reaching over $3.000 \mathrm{kPa}$ at specific points. With these results it is possible to manage the compaction that proved critical at some points, and perform specific soil management, according to the compaction level.

Index terms: compaction, soil depth, geostatistics.
\end{abstract}

\section{INTRODUÇÃO}

O polo Petrolina-PE/Juazeiro-BA, principal região produtora de manga para exportação, já conta com mais de 13 mil hectares de área produzida (PENSA, 2008), podendo ser considerado o maior exemplo de desenvolvimento agrícola em bases irrigadas do Nordeste brasileiro. Com a adoção crescente de tecnologias e o aperfeiçoamento das técnicas de manejo do solo e dessa cultura, essa região tem atingido índices elevados de produtividade nos diferentes tipos de solo, com textura variando de arenosa a muito argilosa, como os Neossolos Quartzarênicos, Argissolos, Latossolos e Vertissolos.

Por ser uma cultura perene, é comum observar, em áreas cultivadas com mangueira, o tráfego de máquinas ou animais no espaço das entrelinhas das plantas, sobre solo desprotegido ou mantido com longos períodos sem revolvimento. Isso pode levar à compactação das camadas. O tráfego de máquinas agrícolas (Collares et al., 2008) e o pisoteio de animais (Flores et al., 2007), nas condições de consistência plástica do solo, provocam deformação e compactação, que se traduzem em aumento da densidade do solo, como resultado da redução da porosidade total, especialmente da macroporosidade (Moraes et al., 2011). Essas alterações repercutem negativamente no processo de troca gasosa do solo (Kaiser et al., 2009) e no aumento da resistência à penetração e, por conseguinte, no desenvolvimento radicular, alterando a produtividade vegetal. Dessa forma, é imprescindível que sejam realizadas avaliações constantes da qualidade física do solo, a fim de monitorar a formação de camadas compactadas.

Por ser um parâmetro de fácil determinação e estar diretamente relacionado com o crescimento das plantas, a resistência mecânica do solo à penetração (RP) tem sido utilizada como indicador da compactação do solo em diversos sistemas de produção (Mercante et al., 2003). Segundo Cunha et al. (2002), esse parâmetro possui diversas aplicações, como deteç̧ão de camadas compactadas, ação de ferramentas de manejo do solo, prevenção de compactação, determinação de força de tração na barra e estudo de processos de umedecimento e ressecamento do solo. Para o caso de Vertissolos, os quais normalmente têm consistência que varia de ligeiramente dura quando secos, friável a firme quando úmidos e muito plástica e muito pegajosa quando molhados, a avaliação e a deteç̧ão de camadas compactadas são de extrema necessidade, visto que esses solos são suscetíveis a mostrar densidade mais elevada.

Segundo Marques (2004), o processo de dispersão natural das argilas é uma característica comum a muitos Vertissolos e contribui para aumentar o grau de limitação física desses solos. No que concerne às práticas conservacionistas, Oliveira (2001) destaca que as características vérticas representam uma séria restrição ao desenvolvimento de vegetais arbóreos, devido ao enraizamento pouco profundo, ao baixo ancoramento radicular e à pouca eficiência na absorção de nutrientes. Ademais, requerem considerável força de tração para as operações de preparo do solo, que são temporariamente limitadas pela estreita faixa ótima de umidade. Como 
parâmetro de comparação, o valor de $2.000 \mathrm{kPa}$ tem sido aceito como o limite crítico de resistência mecânica do solo à penetração para solos argilosos (Secco, 2003).

Como qualquer outro atributo do solo, a resistência mecânica à penetração pode ter elevada variabilidade espacial. Nesse sentido, a geoestatística dispõe de várias técnicas usadas para a análise e inferência de uma variável espacialmente georreferenciada (variáveis regionalizadas), possibilitando o mapeamento de áreas para avaliação do comportamento da variável em estudo e o planejamento mais eficaz da implantação de zoneamento de áreas (Souza et al., 2004). A geoestatística proporciona uma medida da precisão de estimativas, realizadas por meio de um processo de interpolação, a partir de dados amostrados, de modo a dar suporte a uma teoria de estimativas de valores em pontos não amostrados (Faraco, 2006).

O objetivo deste trabalho foi avaliar a variabilidade espacial da resistência mecânica do solo à penetração em área cultivada com manga.

\section{MATERIAL E MÉTODOS}

O trabalho foi conduzido pela equipe do Laboratório de Máquinas e Mecanização Agrícola da Universidade Federal do Vale do São Francisco (UNIVASF), em Vertissolo Háplico (Costa et al., 2008) do perímetro irrigado de Mandacaru, município de Juazeiro - BA, localizado na latitude de $09^{\circ} 23^{\prime} 22,35^{\prime \prime}$ sul, longitude de $40^{\circ} 24^{\prime} 47,28^{\prime \prime}$ oeste e altitude de $380 \mathrm{~m}$. Segundo a classificação de Köppen, o clima é tropical semiárido, tipo BshW, caracterizado por escassez e irregularidade das precipitações, com chuvas no verão e elevada evaporação em consequência das altas temperaturas.

A área é cultivada com manga (Mangifera indica L. cv. Tommy) há mais de 15 anos, em espaçamento de $10 \times 10 \mathrm{~m}$ entre plantas. Os tratos culturais são realizados com tração animal, principalmente para a aplicação de fungicidas, inseticidas e adubos foliares, totalizando quatro operações ao ano, além da colheita.

Realizaram-se análises granulométrica e da umidade atual nas camadas de 0,00-0,10, $0,10-0,20,0,20-0,30$ e $0,30-0,40 \mathrm{~m}$, como forma de caracterização física do solo na projeção da copa das plantas (após operações de manejo) (Quadro 1).

Para avaliação da resistência mecânica do solo à penetração, utilizou-se penetrômetro eletrônico denominado de PenetroLOG® PLG1020 - Medidor Eletrônico de Compactação do Solo (FALKER, 2010). $\mathrm{O}$ medidor segue as recomendações da norma internacional ASAE S.313.3 (ASAE, 1999). Para determinação da posição geográfica dos pontos, foi usado GPS de navegação (Garmin ${ }^{\circledR}$ modelo Etrex Venture HC), configurado para trabalhar com modelo SAD69 - South America Datum, sendo as unidades em UTM - Universal Tranverso de Mercator.

O método para avaliar a espacialização da resistência mecânica do solo à penetração constou da montagem de malha regular de coleta de 50 x $50 \mathrm{~m}$, na projeção da copa da planta próximo ao canal de irrigação, sendo os dados coletados pelo penetrômetro eletrônico até a profundidade de $0,40 \mathrm{~m}$. Para verificar a variabilidade espacial entre os $50 \mathrm{~m}$ de amostragem, criou-se uma micromalha, em que foram coletados os dados de 10 em $10 \mathrm{~m}$ na direção frontal e lateral de caminhamento. Foram coletados 36 pontos, considerando os locais amostrados para a malha regular e a micromalha.

Após a coleta de dados, estes foram descarregados em software específico e transportados para Excel, para posterior realização das análises por camadas: $0,00-0,10,0,10-0,20,0,20-0,30$ e $0,30-0,40 \mathrm{~m}$.

Inicialmente, os dados foram analisados por meio da estatística descritiva, segundo Vieira et al. (2002), obtendo-se média, variância, coeficiente de variação, assimetria e curtose, a fim de se ter uma visão geral do comportamento dos dados. Efetuou-se o teste de Ryan-Joiner, similar ao Shapiro-Wilk, a $1 \%$ para verificar a normalidade dos dados.

Quadro 1. Composição granulométrica para as camadas do Vertissolo Háplico na área de projeção da copa das plantas (após operações de manejo)

\begin{tabular}{|c|c|c|c|c|}
\hline Camada & Argila & Areia & Silte & Umidade \\
\hline $\mathrm{m}$ & 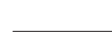 & $\mathrm{kg} \mathrm{kg}^{-1}$ & 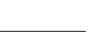 & $\%$ \\
\hline $0,00-0,10$ & 0,260 & 0,409 & 0,331 & 18,5 \\
\hline $0,10-0,20$ & 0,280 & 0,400 & 0,320 & 16,3 \\
\hline $0,20-0,30$ & 0,280 & 0,405 & 0,315 & 16,0 \\
\hline $0,30-0,40$ & 0,280 & 0,380 & 0,340 & 16,9 \\
\hline
\end{tabular}


Para verificar a dependência espacial da resistência mecânica do solo à penetração, foi empregada a análise geoestatística, conforme recomendado por Vieira (2000). Foram construídos semivariogramas, partindo das pressuposições de estacionalidade da hipótese intrínseca e do cálculo da função semivariância e dos ajustes dos modelos teóricos. O ajuste do semivariograma foi observado pelo maior valor do coeficiente de determinação $\left(\mathrm{R}^{2}\right)$, pelo menor valor da soma de quadrados dos desvios (RSS) e pelo maior valor da dependência espacial (ADE). Esse ajuste foi dito como "a sentimento", o qual se escolheu o modelo e respectivos parâmetros, e este é sobreposto aos pontos estimados, verificando-se visualmente a adequação. O processo se repetiu até se encontrar o modelo mais adequado. $\mathrm{O}$ modelo escolhido foi posto à prova por meio da validação cruzada, e, dessa forma, foi possível selecionar não apenas um único modelo, mas um conjunto deles, que pode ser verificado pela validação. Para obtenção dos mapas de isolinhas (bidimensionais) foi utilizado um interpolador (preditor), a krigagem ordinária, permitindo o maior detalhamento espacial do atributo estudado - no caso, a resistência mecânica do solo à penetração.

\section{RESULTADOS E DISCUSSÃO}

\section{Análise descritiva da resistência mecânica do solo à penetração (RP)}

A avaliação da resistência mecânica do solo à penetração $(\mathrm{RP})$ por meio da análise estatística descritiva indicou aumento dos valores à medida que se aprofundaram as camadas, ao mesmo tempo em que houve redução em sua variação ao longo delas (Quadro 2). Os valores de umidade do solo no momento da coleta de RP (Quadro 1) indicam que apenas a camada de 0,00-0,10 m apresentou valor de umidade ligeiramente superior ao das demais camadas: em torno de $16 \%$. Em razão dessa homogeneidade da umidade no perfil do solo, qualquer aumento de RP no perfil ou espacialmente pode ser considerado devido ao manejo. A maior variação ocorrida na camada superficial deve-se a sua exposição às intempéries e seu contato direto com o tráfego de carroças e pisoteio de animais, sobretudo quando as condições de umidade do solo são inadequadas. Em condições de máxima deformação, Choudhury \& Soares (1992) estudaram o sistema radicular da mangueira com oito anos de idade, na região do Submédio São Francisco, e concluíram que, do sistema radicular da planta, $65 \%$ das raízes de absorção e 56 \% das raízes de sustentação distribuem-se de maneira uniforme na camada de 0,00 a $0,60 \mathrm{~m}$. Portanto, a manutenção de adequada qualidade do solo nessa camada torna-se imprescindível para obter alta produtividade na cultura.

Além disso, foi possível observar que nas camadas de 0,20-0,30 m e 0,30-0,40 $\mathrm{m}$ foram obtidos valores máximos de RP superiores a $2.000 \mathrm{kPa}$ em alguns locais da área estudada, podendo atingir valores pontuais superiores a $4.000 \mathrm{kPa}$ em determinadas camadas, como demonstrado no valor de RP máximo do perfil apresentado no quadro 2. Esse fato pode ser explicado pelo não revolvimento do solo por longos períodos e pela acomodação natural das partículas, pois a área é cultivada com

Quadro 2. Estatística descritiva dos dados de resistência mecânica à penetração (kPa)

\begin{tabular}{|c|c|c|c|c|c|c|}
\hline \multirow{2}{*}{$\begin{array}{l}\text { Estatística } \\
\text { descritiva }\end{array}$} & \multicolumn{4}{|c|}{ Camada } & \multirow{2}{*}{$\begin{array}{l}\text { RP Max no } \\
\text { perfil( }^{(3)}\end{array}$} & \multirow{2}{*}{$\begin{array}{l}\text { Prof. da RP } \\
\operatorname{Max}^{(4)}\end{array}$} \\
\hline & $0,00-0,10$ & $0,10-0,20$ & $0,20-0,30$ & $0,30-0,40$ & & \\
\hline & & 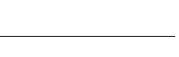 & 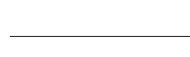 & - & & $\mathrm{m}$ \\
\hline Média & 198,80 & 979,90 & 1400,70 & 1503,00 & 2013 & 0,32 \\
\hline Desvio-Padrão & 193,34 & 268,70 & 330,93 & 306,42 & 687 & 0,07 \\
\hline Variância & 37381,20 & 72184,50 & 109512,66 & 93894,92 & 472047 & 52,20 \\
\hline Mínimo & 16,90 & 563,40 & 906 & 854,90 & 1075 & 0,08 \\
\hline Máximo & 821,90 & 1734,30 & 2282,7 & 2154,20 & 4052 & 0,39 \\
\hline $\mathrm{CV}^{(1)}(\%)$ & 97,30 & 27,42 & 23,62 & 26,06 & 34,13 & 22,70 \\
\hline Assimetria (As) & 1,85 & 0,88 & 0,89 & 0,16 & 1,08 & $-1,27$ \\
\hline Curtose (k) & 2,72 & 0,59 & 0,29 & $-0,09$ & 1,05 & 1,84 \\
\hline Normalidade $\left(\mathrm{R}^{2}\right)$ & 0,87 & 0,97 & 0,96 & 0,96 & 0,96 & 0,96 \\
\hline $\mathrm{P}^{(2)}$ & $<0,010^{* *}$ & $>0,055^{*}$ & $0,033^{* *}$ & $0,039 * *$ & $0,010^{* *}$ & $0,025^{* *}$ \\
\hline
\end{tabular}

(1) CV: coeficiente de variação. ${ }^{(2)} \mathrm{P}$ : probabilidade. ${ }^{(3)} \mathrm{RP}$ Max no perfil: resistência mecânica do solo à penetração máxima no perfil. (4) Prof. da RP Max: profundidade da resistência mecânica do solo à penetração máxima no perfil. *: distribuição normal pelo teste de Ryan-Joiner (similar a Shapiro-Wilk). **: distribuição não normal pelo teste de Ryan-Joiner (similar a Shapiro-Wilk). 
manga sob baixo nível tecnológico há mais de 15 anos. Para Kaiser et al. (2009), valores acima de $2.000 \mathrm{kPa}$ podem representar nível de compactação significativo, o que pode restringir o crescimento radicular de diferentes culturas.

No tocante ao coeficiente de variação (CV) das camadas avaliadas e utilizando a classificação atribuída por Warrick \& Nielsen (1980), a camada de 0,00-0,10 m mostrou CV alto (CV > $62 \%$ ); as demais apresentaram CV considerado médio $(12 \%<\mathrm{CV}<62 \%)$. Souza et al. (2004) encontraram valores de coeficientes de variação médios para a resistência mecânica do solo à penetração em Latossolo Vermelho cultivado com cana-de-açúcar, seguindo a mesma classificação utilizada neste trabalho.

Numericamente, a assimetria (As) pode ser avaliada pelo coeficiente de Pearson (As), o qual demonstrou que os valores de RP em todas as camadas tiveram distribuição assimétrica $(\mid$ As $\mid>0,15)$, sendo classificada como moderada $(0,15<|\mathrm{As}|<1,0)$ para as camadas de 0,10 a 0,20 , 0,20 a 0,30 e 0,30 a $0,40 \mathrm{~m}$, e forte $(|\mathrm{As}|>1,0)$ para a de 0,00 a $0,10 \mathrm{~m}$, na RP máxima do perfil (RPMax) e na profundidade de ocorrência da RPMax.

O coeficiente de curtose $(\mathrm{k})$ é um parâmetro de avaliação em que se observa o grau de achatamento da distribuição, ou seja, o quanto a curva de frequência será achatada em relação a uma curva normal de referência (Accioly, 2011). Nesse caso, somente a camada de 0,00-0,10 m mostrou distribuição platicúrtica ou achatada $(\mathrm{k}>2,63)$, o que demonstra maior intervalo de variação entre os dados, distribuídos em menor frequência na classe modal. Já os demais parâmetros avaliados mostraram $\mathrm{k}<2,63$, o que classifica sua distribuição como leptocúrtica ou alongada, ou seja, os dados caracterizaram-se por menor variação e frequência modal mais acentuada.

Levando-se em consideração as características da variável em estudo, valores atípicos não poderiam ser desprezados (Silveira et al., 2010), pois estes representam a realidade evidenciada em campo, em que a compactação pode-se mostrar de forma pontual e com considerável variabilidade ao longo da área e das camadas avaliadas. Assim, com a utilização da geoestatística, esses valores discrepantes devem ser confrontados com os valores vizinhos a fim de se verificar a necessidade de excluí-los, como fora realizado por Carvalho et al. (2008).

O teste de normalidade de Ryan-Joiner foi utilizado para avaliar se os dados seguem distribuição normal (Quadro 2), pois calcula o coeficiente de correlação entre os dados colocados de forma ordenada em um gráfico de probabilidade normal em relação aos pontos de percentagem a partir da distribuição normal padrão; quanto maior a correlação, maior será a probabilidade de não rejeitar a normalidade (Soares, 2006). A partir do referido teste, constatou-se que somente os dados de RP na camada de 0,10-0,20 m mostraram $p>0,050$, não rejeitando a hipótese nula de normalidade, o que mostra que somente os dados nessa camada seguem distribuição normal. Já os valores de RP nas camadas de $0,00-0,10,0,20-0,30$ e $0,30-0,40 \mathrm{~m}$, RPMax e profundidade de ocorrência da RPMax têm distribuição não normal dos dados. Pelos valores de $\mathrm{R}^{2}$ da normalidade, pode-se observar que somente a camada de 0,00-0,10 m ficou abaixo de 0,96.

\section{Análise geoestatística dos dados de resistência mecânica do solo à penetração (RP)}

A partir da análise do semivariograma para RP, foi possível observar o ajuste do modelo esférico para as camadas avaliadas e o ajuste do modelo exponencial para a análise das resistências máximas (RPMax) e das profundidades de ocorrência das resistências máximas ao longo da área avaliada. Para ambos os modelos, os ajustes apresentaram consideráveis percentuais de significância, demonstrados pelos coeficientes de determinação $\left(R^{2}\right)$ próximos ou iguais a 1,0 (Quadro 3).

Os alcances obtidos foram de 154,6, 108,3, 58,6 e $43,6 \mathrm{~m}$, respectivamente para as camadas de 0,00 a $0,10,0,10$ a $0,20,0,20$ a 0,30 e 0,30 a $0,40 \mathrm{~m}$ de profundidade, demonstrando que, à medida que há aumento na profundidade das camadas avaliadas, ocorre decréscimo na distância entre pontos onde pode-se considerar a existência de dependência espacial entre estes. Já para resistência mecânica do solo à penetração máxima no perfil (RPMax) e para a profundidade da RPMax, os alcances foram de 21,6 e $338,6 \mathrm{~m}$, respectivamente.

Mercante et al. (2003), em trabalho semelhante, em Latossolo, obtiveram alcance entre 51 e $91 \mathrm{~m}$ nas camadas de 0,00 a $0,10,0,10$ a 0,20 e 0,20 a $0,30 \mathrm{~m}$, utilizando malhas de 7,2 x 7,2 m. Já Carvalho et al. (2008) determinaram alcances de 23,03, 36,80 e $12,10 \mathrm{~m}$, respectivamente para as mesmas camadas, em trabalho realizado sob Latossolo, utilizando malha de $20 \times 18,2 \mathrm{~m}$. Observa-se, portanto, que os efeitos sobre o alcance vão depender do tipo e manejo de cada solo, além da quantidade e distribuição das amostras no campo.

O efeito pepita (Co) variou de 4.000 a 1.446 .000 , o que pode refletir diretamente no grau de dependência espacial (ADE). No entanto, mesmo com a elevação do efeito pepita em alguns dos parâmetros, os valores de ADE permaneceram acima de 0,75 para as camadas avaliadas e entre 0,25 e 
0,75 para RPMax e para a profundidade da RPMax, o que, segundo Zimback (2001), é classificado, respectivamente, como forte e moderado grau de dependência espacial.

Para avaliação dos erros de estimativa, foi realizada a validação cruzada dos dados de $R P$, comparando-se os dados reais com os estimados. Como pode ser verificado (Quadro 4), com exceção da camada de 0,30-0,40 m e da análise da profundidade da RPMax, os coeficientes angulares dos demais parâmetros apresentaram-se satisfatoriamente próximos de 1,0, indicando relação próxima de equivalência entre os valores real e estimado. No entanto, o coeficiente de determinação não foi elevado, apresentando-se ainda menos significativo nos parâmetros que mostraram os menores coeficientes angulares. Segundo Paz-Gonzalez et al. (2006), esses resultados podem estar relacionados com o fato de os dados não seguirem distribuição normal, que, apesar de não ser um parâmetro obrigatório, proporciona melhores resultados de estimação.

Os gráficos de isolinhas estimados por krigagem para as camadas de $0,00-0,10,0,10-0,20,0,20-0,30$ e $0,30-0,40$ m da RP são representados nas figuras 1 e 2 e agrupados em classes de cores de ordem crescente.

Pode-se verificar aumento da RP à medida que a profundidade aumenta (Figura 1), não se observando relação direta com a textura e a umidade nas respectivas camadas, o que sugere o efeito do manejo realizado na área sobre o processo de compactação desse solo.

Como essa área é representada pelo cultivo de manga sob baixa tecnologia (colheita manual e tração animal), pode-se pressupor a existência do acúmulo de pressões no solo pelo tráfego de animais e carroças, além do não revolvimento do solo por longos períodos e pela acomodação natural das partículas, como descrito por Carvalho Júnior et al. (1998).

Ainda, ao se observar a figura 1 e com as informações obtidas no quadro 5, nota-se que somente 0,3 e 0,2 \% da área, respectivamente nas camadas de 0,20-0,30 e 0,30-0,40 m, encontramse com RP próxima ou superior a $2.000 \mathrm{kPa}$. No entanto, quando consideradas as resistências máximas pontuais ao longo do perfil, ou seja, sem realizar a média das resistências num intervalo de

Quadro 3. Parâmetros ajustados ao semivariograma da resistência mecânica do solo à penetração (kPa) nas camadas estudadas

\begin{tabular}{|c|c|c|c|c|c|c|}
\hline \multirow{2}{*}{ Parâmetro } & \multicolumn{4}{|c|}{ Camada } & \multirow{2}{*}{$\begin{array}{l}\text { RP Max } \\
\text { no perfil }\end{array}$} & \multirow{2}{*}{$\begin{array}{l}\text { Prof da } \\
\text { RP Max }\end{array}$} \\
\hline & $0,00-0,10$ & $0,10-0,20$ & $0,20-0,30$ & $0,30-0,40$ & & \\
\hline & & & 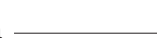 & 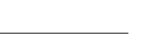 & & $\mathrm{m}$ \\
\hline Modelo & Esférico & Esférico & Esférico & Esférico & Exponencial & Exponencial \\
\hline Efeito Pepita (Co) & 4000 & 13500 & 100,00 & 18500,00 & 1446000,00 & 369000 \\
\hline Patamar $(\mathrm{Co}+\mathrm{C})$ & 50860 & 81390 & 101900,00 & 84050,00 & 450100,00 & 1148900 \\
\hline Variância (C) & 46860 & 67890 & 101800,00 & 65550,00 & 305500,00 & 779900 \\
\hline Alcance (a) & 154,60 & 108,30 & 58,60 & 43,60 & 21,60 & 338,60 \\
\hline $\mathrm{R}^{2(1)}$ & 1,00 & 0,91 & 0,82 & 0,89 & 0,91 & 0,75 \\
\hline $\mathrm{SQR}^{(2)}$ & 73235 & $1,5 \times 10^{8}$ & $7,1 \times 10^{8}$ & $2,9 \times 10^{7}$ & $1,9 \times 10^{3}$ & 110 \\
\hline $\mathrm{ADE}^{(3)}$ & 0,92 & 0,83 & 0,99 & 0,78 & 0,68 & 0,68 \\
\hline Classe & Forte & Forte & Forte & Forte & Moderado & Moderado \\
\hline
\end{tabular}

(1) $R^{2}$ : coeficiente de determinação. ${ }^{(2)}$ SQR: soma dos quadrados dos desvios. ${ }^{(3)}$ ADE: avaliador da dependência espacial.

Quadro 4. Parâmetros da validação cruzada da resistência mecânica do solo à penetração (kPa) nas camadas estudadas

\begin{tabular}{|c|c|c|c|c|c|c|}
\hline \multirow[b]{2}{*}{ Validação Cruzada } & \multicolumn{4}{|c|}{ Camada } & \multirow{2}{*}{$\begin{array}{l}\text { RP Max } \\
\text { no perfil }\end{array}$} & \multirow{2}{*}{$\begin{array}{l}\text { Prof da } \\
\text { RP Max }\end{array}$} \\
\hline & $0,00-0,10$ & $0,10-0,20$ & $0,20-0,30$ & $\overline{0,30-0,40}$ & & \\
\hline & & 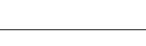 & 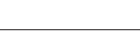 & 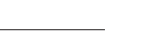 & & $\mathrm{m}$ \\
\hline $\mathrm{R}^{2(1)}$ & 0,60 & 0,52 & 0,44 & 0,13 & 0,23 & 0,03 \\
\hline $\mathrm{A}$ & $-7,06$ & 59,1 & 260,3 & 621,61 & 323,19 & 16,41 \\
\hline b (coef. Angular) & 1,02 & 0,94 & 0,82 & 0,58 & 0,83 & 0,48 \\
\hline
\end{tabular}

(1) $R^{2}$ : coeficiente de determinação. 

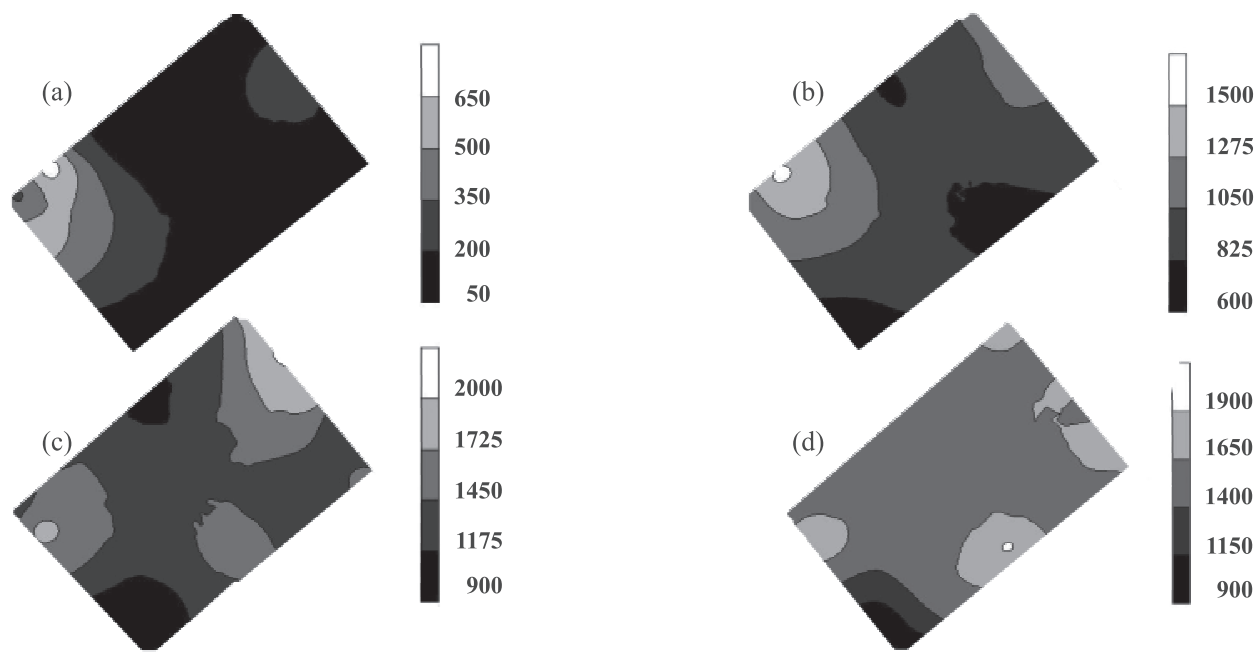

Figura 1. Mapas de krigagem para $\mathrm{RP}(\mathrm{kPa})$ nas camadas avaliadas: (a) 0,00-0,10 m, (b) 0,10-0,20 m, (c) $0,20-0,30 \mathrm{~m}$ e (d) $0,30-0,40 \mathrm{~m}$.

profundidade, foi observado que mais de $70 \%$ da área apresenta zonas com RP acima de $2.000 \mathrm{kPa}$, e 4,4\% dessa mesma área atinge níveis superiores a $3.000 \mathrm{kPa}$. Além disso, das máximas resistências pontuais apresentadas na figura $2 \mathrm{a}$, em torno de $75 \%$ encontram-se no intervalo de 0,30-0,35 m.

Secco (2003) afirma que $2.000 \mathrm{kPa}$ é o valor máximo sugerido, pois acima disso pode haver limitação do crescimento do sistema radicular, além de ocasionar problemas de aeração e de disponibilidade de água para as plantas, o que reduz a produtividade. Em contrapartida, Arshad et al. (1996) afirmam que solos no geral não revolvidos anualmente são toleráveis a valores de resistências até $4.000 \mathrm{kPa}$, devido à permanência e continuidade de poros, atividade biológica mais ativa e maior estabilidade de agregados.

Contudo, a partir dos mapas obtidos, foi possível detectar zonas com padrões de RP uniformes,

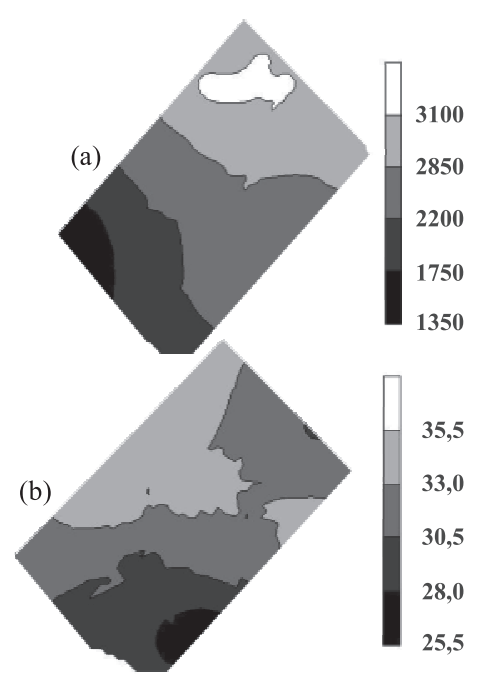

Figura 2. Mapas de krigagem para (a) RP máxima [kPa] e (b) profundidade da $\mathrm{RP}$ máxima $(\mathrm{cm})$.

Quadro 5. Percentagem de área ocupada pelos diferentes níveis de compactação e profundidade dessas camadas

\begin{tabular}{|c|c|c|c|c|c|}
\hline Camada & \multicolumn{5}{|c|}{ Percentual } \\
\hline $\mathrm{m}$ & & & $\%$ & & - \\
\hline $0,00-0,10$ & 75,3 & 16,9 & 7,6 & 4,6 & 0,3 \\
\hline $0,10-0,20$ & 17,6 & 60,3 & 17,0 & 4,8 & 0,3 \\
\hline $0,20-0,30$ & 10,9 & 56,6 & 26,4 & 5,8 & 0,3 \\
\hline $0,30-0,40$ & 2,7 & 5,3 & 74,4 & 17,4 & 0,2 \\
\hline RP Max no perfil & 9,2 & 20,1 & 37,4 & 29,0 & 4,4 \\
\hline Prof. da RP Max & 5,0 & 18,4 & 40,7 & 34,0 & 1,9 \\
\hline
\end{tabular}


possibilitando a adoção de medidas de manejo mais adequadas para cada nível de compactação da área, o que seria impossível a partir de uma análise por métodos descritivos.

\section{CONCLUSÕES}

1. A análise descritiva pelo coeficiente de variação indicou maior variação na camada de 0,00-0,10 m, tendo todas as camadas dependência espacial forte, com exceção das análises de perfil (resistência mecânica do solo à penetração máxima e profundidade da resistência mecânica do solo à penetração máxima), com os maiores alcances nas camadas de $0,00-0,10$ e $0,10-0,20 \mathrm{~m}$.

2. Houve incremento da resistência mecânica do solo à penetração (RP) com o aumento da profundidade, atingindo níveis máximos principalmente entre 0,30 e $0,35 \mathrm{~m}$.

3. As camadas de $0,20-0,30$ e $0,30-0,40 \mathrm{~m}$ mostraram níveis médios de $\mathrm{RP}$ acima de $2.000 \mathrm{kPa}$, considerado crítico.

4. A área avaliada teve considerável distribuição de pontos, com RP acima de $3.000 \mathrm{kPa}$ ao longo do perfil, o que pode interferir na produtividade da cultura nesses locais.

5. Os métodos geoestatísticos permitiram o zoneamento da área, definindo regiões específicas com maiores níveis de compactação (RP), o que possibilita o manejo localizado nessa área.

\section{LITERATURA CITADA}

ACCIOLY, C.V. Assimetria e curtose (Aula 10). Disponível em: $<$ http://www1.eeg.uminho.pt/economia/priscila/intocaveis/ FMIE04/links/assimetriacurtose.pdf $>$. Acesso em: $11 \mathrm{de}$ abr. de 2011.

AMERICAN SOCIETY OF AGRICULTURAL ENGINEERS ASAE S313.3: Soil cone penetrometer. St. Joseph, 1999. 834p.

ARSHAD, M.A.; LOWERY, B. \& GROSSMAN B. Physical tests for monitoring soil quality. In: DORAN, J.W. \& JONES, A.J., eds. Methods for assessing soil quality. Madison, Soil Science Society of America, 1996. p.123-141 (SSSA Special Publication, 49)

CARVALHO JÚNIOR, I.A.; FONTES, L.E.F. \& COSTA, L.M. Modificações causadas pelo uso e formação de camadas compactadas e, ou, adensadas em um Latossolo VermelhoEscuro textura média, na região do Cerrado. R. Bras. Ci. Solo, 22:505-514, 1998.
CARVALHO, L.A.; VALDEMAR NETO, V.J.; SILVA, L.F.; PEREIRA, J.G.; NUNES, W.A.G.A. \& CHAVES, C.H.C. Resistência mecânica do solo à penetração (RMP) sob cultivo de cana-de-açúcar, no município de Rio Brilhante-MS. Agrarian, 1:7-22, 2008.

PENSA - Centro de Conhecimento em Agronegócios. Projeto integrado de negócios sustentáveis - PINS: Cadeia Produtiva de Piscicultura/Centro de Conhecimento em Agronegócios (PENSA). Brasília, CODEVASF, 2008. 38p.

CHOUDHURY, E.N. \& SOARES, J.M. Comportamento do sistema radicular de fruteiras irrigadas. I. Mangueira em solo arenoso sob irrigação por aspersão sob copa. R. Bras. Frutic., 14:169-176, 1992.

COLLARES, G.L.; REINERT, D.J.; REICHERT, J.M. \& KAISER, D.R. Compactação de um Latossolo induzida pelo tráfego de máquinas e sua relação com o crescimento e produtividade de feijão e trigo. R. Bras. Ci. Solo, 32:933-942, 2008.

COSTA, N.D.; ARAUJO J.F.; SANTOS, C.A.F.; RESENDE, G.M. \& LIMA, M.A.C. Desempenho de cultivares de cebola em cultivo orgânico e tipos de solo no Vale do São Francisco. Hortic. Bras., 26:476-480, 2008.

CUNHA, J.P.A.R.; VIEIRA, L.B. \& MAGALHÃES, A.C. Resistência mecânica do solo à penetração sob diferentes densidades e teores de água. Eng. Agric., 10:1-7, 2002.

FALKER. PenetroLOG PLG1020 - Medidor Eletrônico de Compactação do Solo. Disponível em: < http://www.falker. com.br/download.php> . Acesso em: 23 set. de 2010.

FARACO, M.A. Qualidade do ajuste de modelos geoestatísticos utilizados na agricultura de precisão. Cascavel, Universidade Estadual do Oeste do Paraná, 2006. 116p. (Tese de Mestrado)

FLORES, J.P.C.; ANGHINONI, I.; CASSOL, L.C.; CARVALHO, P.C.F.; LEITE, J.G.D.B. \& FRAGA, T.I. Atributos físicos do solo e rendimento de soja em sistema plantio direto em integração lavoura-pecuária com diferentes pressões de pastejo. R. Bras. Ci. Solo, 31:771-780, 2007.

KAISER, D.R.; REINERT, D.J.; REICHERT, J.M.; COLLAGES, G.L. \& KUNS, M. Intervalo hídrico ótimo no perfil explorado pelas raízes de feijoeiro em um latossolo sob diferentes níveis de compactação. R. Bras. Ci. Solo, 33:845$855,2009$.

MARQUES, F.A. Caracterização de solos da ilha de Fernando de Noronha. Recife, Universidade Federal Rural de Pernambuco, 2004. 101p. (Tese de Mestrado)

MERCANTE, E.; URIBE-OPAZO, M.A. \& SOUZA, E.G. Variabilidade especial e temporal da resistência mecânica do solo à penetração em áreas com e sem manejo químico localizado. R. Bras. Ci. Solo, 27:1149-1159, 2003.

MORAES, M.T.; DEBIASI, H.; FRANCHINI, J.C. \& SILVA, V.R. Propriedades físicas do solo sob diferentes níveis de compactação em um Latossolo Vermelho distroférrico. In: JORNADA ACADÊMICA DA EMBRAPA SOJA, 6., Londrina, 2011. Resumos expandidos. Londrina, Embrapa Soja, 2011. p.51-55. (Embrapa Soja. Documentos, 328) 
OLIVEIRA, J.B. Pedologia aplicada. Jaboticabal, FUNEP, 2001. $414 \mathrm{p}$.

PAZ-GONZALEZ, A.; TABOADA CASTRO, M.T. \& VIEIRA, S.R. Geostatistical analysis of heavy metals in a one-hectare plot under natural vegetation in a serpentine area. Can. J. Soil Sci., 81:469-479, 2001.

SECCO, D. Estados de compactação de dois latossolos sob plantio direto e suas implicações no comportamento mecânico e na produtividade de culturas. Santa Maria, Universidade Estadual de Santa Maria, 2003. 108p. (Tese de Doutorado)

SILVEIRA, D.C.; MELO FILHO, J.F.; SACRAMENTO, J.A.A.S. \& SILVEIRA, E.C.P. Relação umidade versus resistência à penetração para um Argissolo Amarelo distrocoeso no recôncavo da Bahia. R. Bras. Ci. Solo, 34:659-667, 2010.

SOARES, A.A. O índice de capacidade multivariado como instrumento para avaliação do processo em uma operação de usinagem. Florianópolis, Universidade Federal de Santa Catarina, 2006. 114p. (Tese de Mestrado)

SOUZA, Z.M.; MARQUES JUNIOR, J. \& PEREIRA, G.T. Variabilidade espacial de atributos físicos do solo em diferentes formas do relevo sob cultivo de cana-de-açúcar. R. Bras. Ci. Solo, 28:937-944, 2004.
VIEIRA, S.R. Geoestatística em estudos de variabilidade espacial do solo. In. NOVAIS, R.F.; ALVAREZ V., V.H.; SCHAEFER, C.E.G.R., eds. Tópicos em ciência do solo. Viçosa, MG: Sociedade Brasileira de Ciência do Solo, 2000. v.1. p.2-54.

VIEIRA, S.R.; MILLETE, J.; TOPP, G.C. \& REYNOLDS, W.D. Handbook for geoestatistical analysis of variability in soil and climate data. In: ALVAREZ, V.V.H.; SCHAEFER, C.E.G.R.; BARROS, N.F.; MELLO, J.W.V. \& COSTA, J.M., eds. Tópicos em ciência do solo. Viçosa, MG, Sociedade Brasileira de Ciência do Solo, 2002. v.2. p.1-45.

ZIMBACK, C.R.L. Análise espacial de atributos químicos de solos para fins de mapeamento da fertilidade. Botucatu, UNESP, 2001. 114f. (Tese de Livre-Docência)

WARRICK, A.W. \& NIELSEN, D.R. Spatial variability of soil physical properties in the field. In: HILLEL, D., ed. Applications of soil physics. New York, Academic Press, 1980. 
